\title{
Test purchase of new synthetic tryptamines via the Internet: Identity check by GC-MS and separation by HPLC
}

\author{
Magdalena Taschwer, Edith Ebner, Martin G Schmid* \\ Department of Pharmaceutical Chemistry, Institute of Pharmaceutical Sciences, University of Graz, Universitätsplatz 1, A-8010 Graz, Austria.
}

\begin{tabular}{|c|c|}
\hline ARTICLE INFO & ABSTRACT \\
\hline Article history: & \multirow{10}{*}{$\begin{array}{l}\text { Over the past few years, a continuous alteration of the recreational drug market took place. Among other novel } \\
\text { psychoactive drugs, new synthetic tryptamine derivatives appeared on the market. These compounds are mainly } \\
\text { traded via the Internet, which has become an important marketplace for the sale of recreational drugs. The goal of } \\
\text { our research was to check, if } 13 \text { new synthetic tryptamines obtained by test purchase via different online vendors } \\
\text { meet the promised identity. Analysis was performed by GC-MS, using a common } 30 \text { m HP-5MS capillary } \\
\text { column as stationary phase. Subsequently, a simple HPLC method for the separation of these tryptamines was } \\
\text { developed. Therefore, the aim was to establish a method to separate a broad spectrum of trypamines } \\
\text { simultaneously within short time. Measurements were performed by a LiChrospher }{ }^{\circledR} \text { RP-18e column and a } \\
\text { mobile phase consisting of } 0.1 \% \text { triethylammonium acetate buffer, methanol and acetonitrile. Both presented } \\
\text { methods were found to be suitable for the identification as well as separation of tryptamines as the analysis times } \\
\text { were short and the selectivity sufficient. Moreover, enantioseparation of } 3 \text { chiral tryptamine derivatives } \\
\text { purchased via the Internet by HPLC-UV and an Astec }{ }^{\circledR} \text { Cyclobond ITM } 2000 \text { as CSP was performed. All of them } \\
\text { were sold as racemic mixtures. }\end{array}$} \\
\hline Received on: 25/09/2015 & \\
\hline Revi & \\
\hline 015 & \\
\hline Available online: $26 / 01 / 2016$ & \\
\hline Key words: & \\
\hline Tryptamines, Legal highs, & \\
\hline Novel psychoactive drugs, & \\
\hline HPLC, GC-MS. & \\
\hline & \\
\hline
\end{tabular}

\section{INTRODUCTION}

Over the past decade the availability and diversity of novel psychoactive drugs on the European drug market has progressively increased. According to the European Drug Report 2015, 101 new and not previously reported psychoactive compounds were reported in 2014. Compared with the drug report of 2013 this represents an increase of 25\%. Besides synthetic cathinones, cannabinoids, opioids, phenetylamines and arylamines, synthetic tryptamines represent a further group of misused psychoactive substances (EMCDDA, 2015). Tryptamine, a monoamine alkaloid, and its derivatives can be found in plants, fungi and animals. Lots of organisms, especially plants, produce tryptamines as metabolites. Substances with a tryptamine-similar structure are e.g. the neurotransmitter serotonin, melatonin and the amino acid tryptophan. Well-known natural representatives are the hallucinogens of magic mushrooms, namely psilocybin and its hydrolysis product psilocin. A further metabolite derived from tryptamines is the alkaloid bufotenin, which exists in the skin of some species of toads of the genus Bufo (Gibbons, 2012). Besides the naturally

\footnotetext{
* Corresponding Author

Martin G Schmid, Department of Pharmaceutical Chemistry, Institute of Pharmaceutical Sciences, University of Graz, Universitätsplatz 1, A8010 Graz, Austria.Email: martin.schmid@uni-graz.at
}

occurring tryptamines, there is a huge spectrum of synthetic derivatives. Via substitution at the aromatic ring or at the nitrogen atom a diversified range of legal psychoactive compounds is given. Hallucinogenic tryptamines bear a substituted tryptamine structure. The indole ring, which is a particular structure of the tryptamines, is known from other substances such as lysergic acid diethylamide (LSD). Due to the fact that tryptamines show a similar but a bit weaker psychoactive effect than LSD, this compound class is used as legal alternative for LSD (Araujo et al., 2015). The effects of tryptamines include a marked release and inhibited reuptake of serotonin. In addition to the hallucinations, the psychotropic effects of the tryptamines also cover euphoria, empathy and a feeling of love. Furthermore, visual and auditory disturbances and distortions may occur. Because of the mind-expanding effect, these substances have become popular in the drug scene, where they are called "happy pills", "love pills" or "hi-trips".

Due to the psychotropic effects, tryptamines have been used for medical purposes and religious ceremonies since ancient times. There are different traditional ways how shamans and natives have applied them for rituals, healing ceremonies or recreational use. They can either be used as a powder, which is insufflated or snuffed, as hallucinogenic drink or as magic mushrooms (also known as psychedelic mushrooms). In South 
America and on the West-Indian islands the seeds, which contain hallucinogenic tryptamine derivatives, (e.g. dimethyltryptamine (DMT), bufotenin and 5-methoxy- $N, N$-dimethyltryptamine (5MeO-DMT)) of Anadenanthera species are grinded to powder. Identified as "yopo" or "cohoba", this powder is snuffed or blown through a bamboo tube into the nostrils. "Epena", a hallucinogenic tryptamine rich powder from the Virola species, is still used as insufflation from the medicine men from the Amazon. "Ayahuasca", which has its origin at the Amazon too, is a sacred brew of the indigenous population. It is mainly prepared out of stems of Banisteriopsis caapi and leaves of Psychotria viridis and Diplopterys cabrerana. Dependent from the part of the plant and the origin, the main components are DMT, 5-MeO-DMT and the MAO-inhibitors harmine and harmaline (Arunotayanun and Gibbons, 2012). There are worldwide over 100 sorts of mushrooms. But in Europe, the most common one is the Psilocybe semilanceata, better known as liberty cap. The ingredients of the hallucinogenic mushrooms are mainly psilocin, psilocybin, baeocystin and norbaeocystin.

Dipropyltryptamine (DPT), diethyltryptamine (DET), DMT as well as other methoxytryptamines were the first fully synthetic prepared tryptamines. Since DMT was used as additive to prepare the ayahuasca decoctions in the Amazon for centuries, it was synthesized the first time by the Canadian chemist Richard Helmuth Fredrick Manske in 1931 (Manske, 1931).

Some tryptamine derivatives synthesized for pharmaceutical purposes e.g. sumatriptan or zolmitriptan (for migraine treatment) are misused as recreational drugs by addicts (UNODC, 2013).

The American chemist Alexander Shulgin dedicated his research also to tryptamines. After his former book PiHKAL he synthesized a large number of derivatives of this compound class and published the methods of the syntheses as well as the dosage conditions in his book TiHKAL ("Tryptamines I Have Known And Loved") (Shulgin and Shulgin, 1991; Shulgin and Shulgin, 1997).

In literature, several articles dealing with analysis, identification and separation by various separation techniques of novel psychoactive compounds, including tryptamines as new compound class, are available. Some articles report on a comparison of separation methods including HPLC, CE and GC for tryptamines (Wang et al., 2008; Brandt and Martins, 2010).

Recently, Armenta and his group detected and characterized amphetamines, cathinones, tryptamines and synthetic cannabinoids by ion mobility spectrometry (Armenta et al., 2015).

Arunotayanun et al. reported on the structure elucidation as well as receptor binding profiles of the synthetic tryptamines $\alpha$ methyltryptamine and 5-methoxy- $N, N$-diallyltryptamine (Arunotayanun et al., 2013).

In 2013 Kanu et al. successfully analysed and identified psychoactive cathinones and tryptamines using APIM (TOF)-MS (atmospheric pressure ion mobility time-of-flight mass spectro- meter) (Kanu et al., 2013).

Moreover several papers deal with the analysis of traditional dosage forms of tryptamines, especially ayahuasca (Gabelunghe et al., 2008; McIlhenny et al., 2009; Pires et al., 2009; Gaujac et al., 2013).

Additionally, literature about the synthesis and cytotoxic properties (Salikov et al., 2015) as well as characterization of psychotropic tryptamines is available (Brandt et al., 2010; Tearavarich et al., 2011; Brandt et al., 2012; Elliott et al., 2013). Hsiao and co-workers reported on the simultaneous separation and detection of phenetylamine and tryptamine derivatives using HPLC-UV and LC/ESI MS (Hsiao et al., 2009).

In 2015, LC-MS/MS was reported to be successful for screening procedures, detection as well as quantification of novel psychoactive drugs including tryptamine derivatives in blood (Adamovicz and Tokarczyk, 2015; Ambach et al., 2015) and urine (Ambach et al., 2015) samples.

In Austria, tryptamines are controlled by the Novel Psychoactive Substances Law (NPSG, BGBl.I Nr. 48/2013). According to this new law only trade of new psychoactive compounds such as novel tryptamines is prohibited.

Since different new tryptamines were seized by Austrian police during the last years they represent an important category of novel psychoactive drugs (NPDs). Due to an increased availability of these compounds on the illicit drug market and the fact that they are often used as an alternative to illegal drugs such as LSD, this compound class has developed to a social problem.

A remarkable spectrum of synthetic tryptamines is available via the Internet. In order to prove purity of the offered compounds online vendors disclose product analyses by nuclear magnetic resonance (NMR) and mass spectroscopy (MS) on their Internet pages. However, data of the published information can not be verified. Thus, the aim of our work was to check identity of 13 synthetic tryptamines purchased by mystery shopping between the years 2012 and 2014 via the Internet by GC-MS. To be precise, 5API (5- (2-aminopropyl)indole) is a positional isomer of AMT ( $\alpha$ methyltryptamine) and belongs chemically rather to phenethylamines than to the compound class of tryptamines.

Four tryptamine derivatives were additionally bought as research chemicals from an official supplier in order to separate them simultaneously with the test purchased compounds. Since these commercially available chemicals were analytical standards there was no need to to prove their identity. Afterwards a separation method by HPLC was developed.

Generally, chiral recreational drugs are traded as racemates and thus their enantiomers may show different pharmacological effects, as it is known from several chiral pharmaceutical ingredients, cathinones and amphetamine.

As 3 of the 17 tryptamine derivatives investigated possess a stereogenic centre, a further emphasis of this contribution was enantioseparation by HPLC-UV to check, if the purchased samples were sold as racemic mixtures or pure enantiomers. 


\section{MATERIALS AND METHODS}

\section{Chemicals and reagents}

All chemicals were of analytical grade. Acetonitrile $(\mathrm{ACN})$, methylene chloride, methanol, phosphoric acid (85\%), sodium hydroxide and anhydrous sodium sulfate were obtained from VWR (Darmstadt, Germany). Triethylamine (TEA) and acetic acid (100\%) were purchased from Sigma-Aldrich (St. Louis, MO, USA). Ultra-pure water was prepared in our laboratory (Millipore, Darmstadt, Germany). Because of their novelty, the majority of the analytes were not available at official suppliers and therefore they were purchased from different Internet shops. 5MeO-DALT (5-methoxy- $N, N$-diallyltryptamine) was from viplegals.com. 5-API (5- (2-aminopropyl)indole) was bought from sensearomatic.com. MiPT ( $N$-methyl- $N$-isopropyltryptamine), 5 MeO-DMT, 5-MeO-DiPT (5-methoxy- $N, N$-diisopropyl tryptamine), 4-MeO-MiPT (4-methoxy- $N$-methyl- $N$-isopropyl tryptamine), 4$\mathrm{OH}-\mathrm{MiPT}$ (4-hydroxy- $N$-methyl- $N$-isopropyl tryptamine), 4-OHMET (4-hydroxy- $N$-methyl- $N$-ethyl tryptamine), 4-AcO-DPT (4acetoxy- $N$-dipropyltryptamine), 4-AcO-DiPT (4-acetoxy- $N, N$ diisopropytryptamine), 4-AcO-DET (4-acetoxy- $N, N$ diethyltryptamine), 5-MeO-MiPT (5-methoxy- $N$-methyl- $N$ isopropyltryptamine) were obtained from buybestrc.com. AMT ( $\alpha-$ methyltryptamine) was from futurelabs.eu. DiBT $(N, N-$ diisobutyltryptamine), DPT ( $N, N$-dipropyltryptamine), DALT $(N, N$-diallyltryptamine $) \quad$ and $\quad N$-OH-AMT $\quad(N$-hydroxy- $\alpha-$ methyltryptamine) were obtained from THC Pharm $\mathrm{GmbH}$ (Frankfurt/Main, Germany). Prior to separation experiments, compounds were characterized by gas chromatography-electron impact mass spectrometry and if necessary by NMR. Table 1 shows the chemical structure of the investigated tryptamines.

\section{Instrumentation}

\section{Gas chromatography-mass spectrometry}

GC-MS was carried out with an Agilent (Waldbronn, Germany) HP 6890 GC coupled to an Agilent (Waldbronn, Germany) HP 5972 mass selective detector. As stationary phase an HP-5MS capillary column with a length of $30 \mathrm{~m}$, an inner diameter of $250 \mu \mathrm{m}$ and film thickness of $0.25 \mu \mathrm{m}$ was used. The column temperature program was as follows: the initial oven temperature was held at $50^{\circ} \mathrm{C}$ for $1 \mathrm{~min}$, before continuous increase to $310^{\circ} \mathrm{C}$ $\left(10^{\circ} \mathrm{C} / \mathrm{min}\right)$. Afterwards, the column temperature was held at the final temperature $\left(310^{\circ} \mathrm{C}\right)$ for $3 \mathrm{~min}$. Helium served as mobile phase at a maintaining flow rate of $0.8 \mathrm{ml} / \mathrm{min}$. Injection $(1 \mu \mathrm{l})$ was performed automatically with a split ratio of $2: 1$ at an inlet temperature of $280^{\circ} \mathrm{C}$. To elucidate the mass fragments of each tryptamine, data were received in scan mode with a scan range of $\mathrm{m} / \mathrm{z}$ 35-400 with $4 \mathrm{~min}$ solvent delay. Data collection was performed with MSD Chemstation Rev. E. 02.00 .493 (Agilent Technologies, CA, USA) software.

\section{High-performance liquid chromatography}

HPLC analyses were performed using an HP Hewlett Packard Series II, 1090, Liquid Chromatograph, provided with an autosampler and a diodearray detector. Measurements were done at $35^{\circ} \mathrm{C}$ under isocratic conditions with a flowrate of $1 \mathrm{ml} / \mathrm{min}$ and an injection volume of $5 \mu \mathrm{l}$. Ultraviolet detection was carried out at $280 \mathrm{~nm}$. Data evaluation was peformed with a Chemstation Rev. A. 0903 (Agilent Technologies, Waldbronn, Germany) software. A LiChrospher ${ }^{\circledR} 100 \mathrm{RP}-18 \mathrm{e}, 250 \mathrm{~mm}$ x 4 mm, $5 \mu \mathrm{m}$ from Merck KGaA (Darmstadt, Germany) served as stationary phase.

Enantioseparation measurements were carried out using an Agilent 1100 Series Liquid Chromatograph, equipped with an autosampler and an UV-detector. The column compartment was maintained at $25{ }^{\circ} \mathrm{C}$. Chiral separation was performed under isocratic conditions at a flow rate of $0.6 \mathrm{ml} / \mathrm{min}$. Experiments were conducted with an injection volume of $1 \mu \mathrm{l}$ and a wavelength of $240 \mathrm{~nm}$. Data processing was done with a ChemStation for LC 3D Systems Rev. B. 04.03 (Agilent Technologies, Waldbronn, Germany) software. As chiral stationary phase an Astec $^{\circledR}$ Cyclobond I ${ }^{\mathrm{TM}}$ 2000, $250 \mathrm{~mm} \times 4.6$ $\mathrm{mm}, 5 \mu \mathrm{m}$ from Sigma-Aldrich (St. Louis, MO, USA) was used.

Mobile phases were prepared by mixing the components in the required ratios. Afterwards the solutions were degassed for 2 minutes with helium and filtered through a $0.45 \mu \mathrm{m}$ pore size cellulose filter (Carl Roth, Karlsruhe, Germany).

\section{Sample preparation}

For GC-MS, the basic aqueous solution of the analytes was extracted with methylene chloride to obtain the free base of the compounds in the organic layer. Therefore, $0.5 \mathrm{mg}$ of each analyte was dissolved in $1.5 \mathrm{ml}$ nanopure water, $20 \mu \mathrm{l}$ of $0.2 \mathrm{~N}$ $\mathrm{NaOH}$ were added and extraction was performed by $1.5 \mathrm{ml}$ methylene chloride. The organic solvent, which contained the free base, was dried over anhydrous sodium sulfate.

As sample preparation for HPLC experiments, $0.5 \mathrm{mg}$ of each analyte was dissolved in $1 \mathrm{ml}$ nanopure water and ultrasonicated for $1 \mathrm{~min}$. In case of low solubility, $10 \mu \mathrm{l}$ methanol and $10 \mu \mathrm{l} 2 \mathrm{~N}$ hydrochloric acid were added.

\section{RESULTS AND DISCUSSION}

Tryptamines with various substitution patterns show psychedelic activity. Many of the tryptamine derivatives show an unspecific binding profile and exhibit a neuronal interaction with 5-HT serotonin receptor subtypes. It is presumed that the agonistic activity at $5-\mathrm{HT}_{2 \mathrm{~A}}$ receptor is primarily responsible for the psychedelic effects.

Generally, all 17 analytes are basic compounds and can be structurally divided in 5 groups: a) tryptamines without any substituent on the indol ring, b) tryptamines with an acetoxy group on position 4 of the indol ring, c) tryptamines with a methoxy group on position 4 or 5 of the indol ring, d) tryptamines with a hydroxy group on position 4 of the indol ring and e) indol derivatives (Table 1). 
Table 1: Chemical structure of the tryptamines investigated in this study.

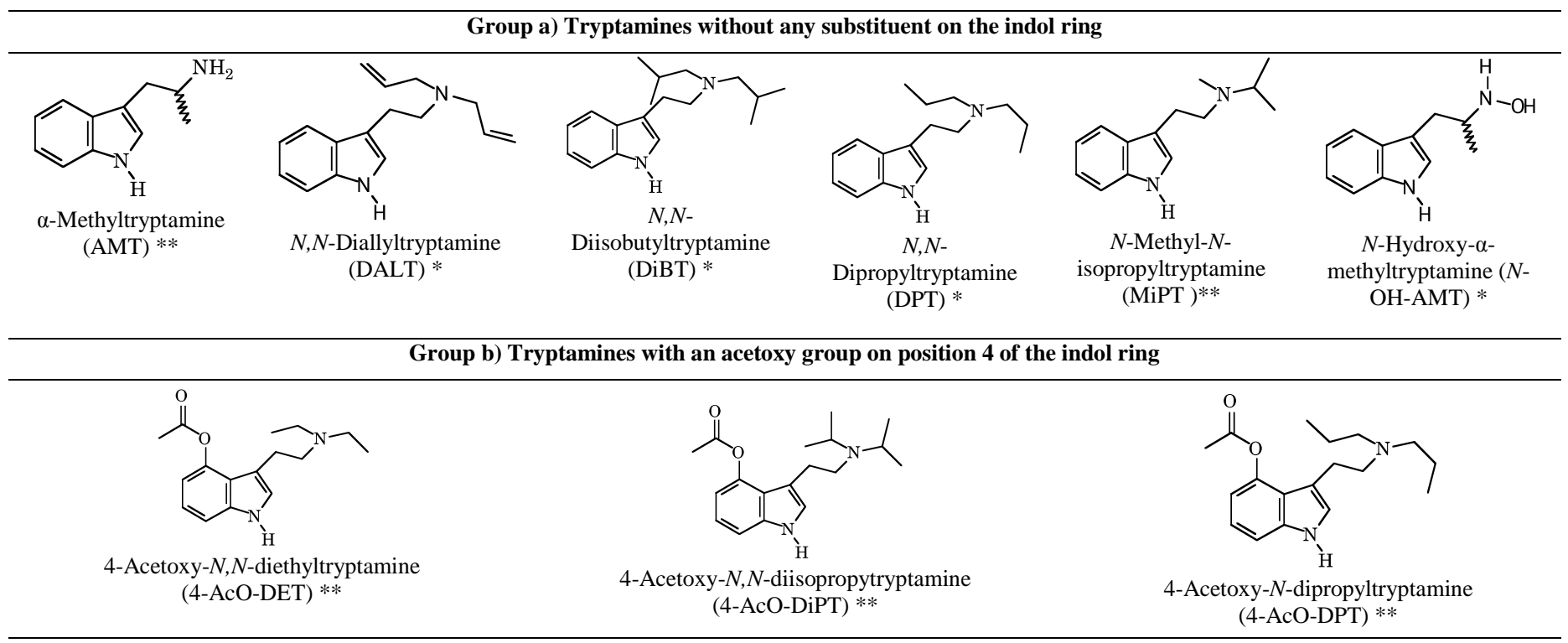

Group c) Tryptamines with a methoxy group on position 4 or 5 of the indol ring<smiles>C=CCN(CC=Cc1c[nH]c2ccc(OC)cc12)CCC</smiles>

5-Methoxy- $N, N$ diallyltryptamine $(5-\mathrm{MeO}-\mathrm{DALT}) * *$

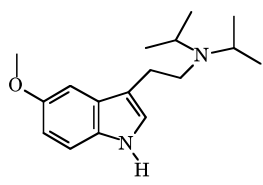

5-Methoxy- $N, N$ diisopropyltryptamine $(5-\mathrm{MeO}-\mathrm{DiPT}) * *$

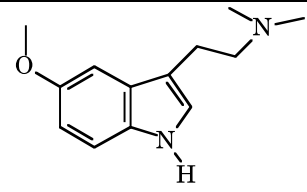

5-Methoxy- $N, N-$ dimethyltryptamine $(5-\mathrm{MeO}-\mathrm{DMT}) * *$<smiles>COc1cccc2[nH]cc(CCN(C)C(C)C)c12</smiles>

4-Methoxy- $N$-methyl- $N$ isopropyltryptamine $(4-\mathrm{MeO}-\mathrm{MiPT}) * *$

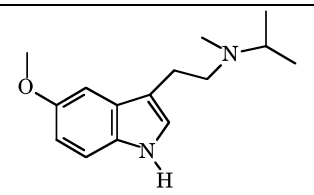

5-Methoxy- $N$-methyl- $N$ isopropyltryptamine (5-MeO-MiPT) **

Group d) Tryptamines with a hydroxy group on position 4 of the indol ring
5- (2-Aminopropyl) Indole (API) **
(4-OH-MET) $* *$

* obtained from an official supplier, ** obtained via mystery shopping.

\section{Analysis and identification of tryptamines by gas chromatography}

Gas chromatography was mainly performed to verify identity with the coupled MS-detector. In Table 2, analysis data including retention time, molecular formula, molecular weight and characteristic main fragment are presented. Retention times ranged between 15 and 23 minutes, which correlated well with increasing molecular weight. Comparing retention times of tryptamines bearing no substituents on the indol ring and those of tryptamines, which contain a methoxy or acetoxy group, retention times increased with functional groups. Regarding 4-MeO-MiPT and 4-OH-MiPT, which differ only in the methoxy or hydroxy group on the indol ring, it is obvious that the functional groups cause only slight differences of effects on the selectivity and on the interaction of the compounds and the stationary phase.

By means of retention time, molpeak and main fragment of each compound, listed in Table 2, identification of all 17 analytes was possible. With this GC method, up to 8 tryptamines were separated simultaneously. In Fig. 1 a chromatogram of 8 resolved tryptamines is presented.

Additionally, a further method for separation of novel psychoactive drugs by HPLC was developed. 


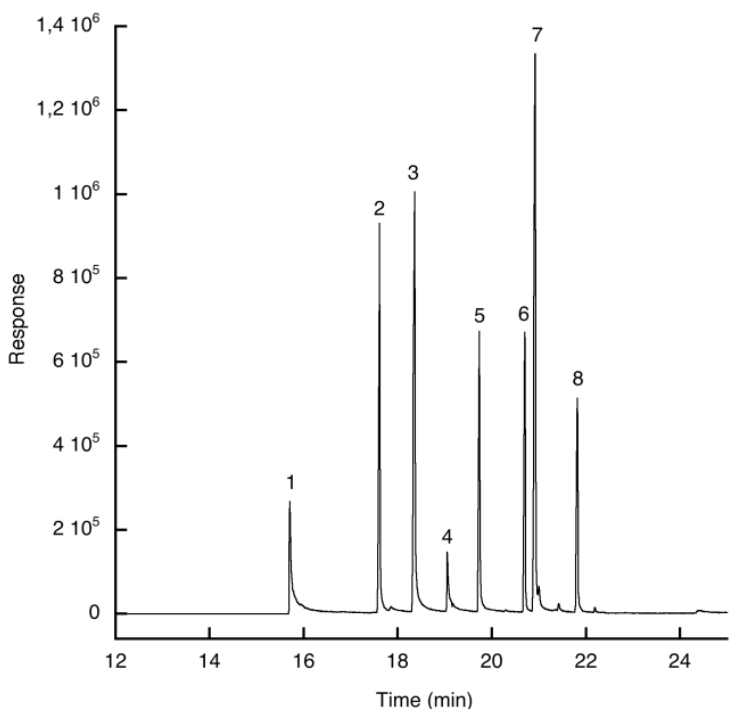

Fig. 1: Simultaneous identification of (1) AMT, (2) MiPT, (3) 5-MeO-DMT, (4) 4-OH-MET, (5) 5-MeO-MiPT, (6) 5-MeO-DiPT, (7) 5-MeO-DALT, (8) 4AcO-DiPT by GC-MS. Conditions: Capillary column: $30 \mathrm{~m}$ x $250 \mu \mathrm{m} \times 0.25$ $\mu \mathrm{m}$ nominal, HP-5MS 5\% phenyl methyl siloxane; mobile phase: helium; temperature profile: $1 \mathrm{~min} 50^{\circ} \mathrm{C}, 10^{\circ} \mathrm{C} / \mathrm{min}$ to $310^{\circ} \mathrm{C}, 3 \mathrm{~min}$ postrun; flow: 0.8 $\mathrm{ml} / \mathrm{min}$; injection: $1 \mu \mathrm{l}$.

Table 2: Retention time, molecular formula, molecular weight and main fragment of the 17 analysed tryptamines by GC-MS.

\begin{tabular}{ccccc}
\hline Compound & $\begin{array}{c}\mathbf{R t} \\
(\mathbf{m i n})\end{array}$ & $\begin{array}{c}\text { molecular } \\
\text { formular }\end{array}$ & $\begin{array}{c}\text { Mr } \\
\text { (g/mol) }\end{array}$ & $\begin{array}{c}\text { Main fragment } \\
(\mathbf{m} / \mathbf{z})\end{array}$ \\
\hline 4-AcO-DET & 20.95 & $\mathrm{C}_{16} \mathrm{H}_{22} \mathrm{~N}_{2} \mathrm{O}_{2}$ & 274.36 & 86 \\
4-AcO-DiPT & 22.05 & $\mathrm{C}_{18} \mathrm{H}_{26} \mathrm{~N}_{2} \mathrm{O}_{2}$ & 302.42 & 114 \\
4-AcO-DPT & 22.24 & $\mathrm{C}_{18} \mathrm{H}_{26} \mathrm{~N}_{2} \mathrm{O}_{2}$ & 302.42 & 114 \\
AMT & 15.93 & $\mathrm{C}_{11} \mathrm{H}_{14} \mathrm{~N}_{2}$ & 174.24 & 44 \\
DALT & 18.93 & $\mathrm{C}_{16} \mathrm{H}_{20} \mathrm{~N}_{2}$ & 240.34 & 110 \\
DiBT & 19.69 & $\mathrm{C}_{18} \mathrm{H}_{28} \mathrm{~N}_{2}$ & 272.43 & 142 \\
DPT & 18.97 & $\mathrm{C}_{16} \mathrm{H}_{24} \mathrm{~N}_{2}$ & 244.38 & 114 \\
5-API & 15.97 & $\mathrm{C}_{11} \mathrm{H}_{14} \mathrm{~N}_{2}$ & 174.24 & 44 \\
5-MeO-DALT & 21.14 & $\mathrm{C}_{17} \mathrm{H}_{22} \mathrm{~N}_{2} \mathrm{O}$ & 270.37 & 110 \\
5-MeO-DiPT & 20.93 & $\mathrm{C}_{17} \mathrm{H}_{26} \mathrm{~N}_{2} \mathrm{O}$ & 274.40 & 114 \\
5-MeO-DMT & 18.53 & $\mathrm{C}_{13} \mathrm{H}_{18} \mathrm{~N}_{2} \mathrm{O}$ & 218.29 & 58 \\
4-MeO-MiPT & 19.64 & $\mathrm{C}_{15} \mathrm{H}_{22} \mathrm{~N}_{2} \mathrm{O}$ & 246.35 & 86 \\
5-MeO-MiPT & 19.99 & $\mathrm{C}_{15} \mathrm{H}_{22} \mathrm{~N}_{2} \mathrm{O}$ & 246.35 & 86 \\
MiPT & 17.81 & $\mathrm{C}_{14} \mathrm{H}_{20} \mathrm{~N}_{2}$ & 216.33 & 86 \\
N-OH-AMT & 16.11 & $\mathrm{C}_{11} \mathrm{H}_{14} \mathrm{~N}_{2} \mathrm{O}$ & 190.24 & 130 \\
4-OH-MET & 19.29 & $\mathrm{C}_{13} \mathrm{H}_{18} \mathrm{~N}_{2} \mathrm{O}$ & 218.29 & 72 \\
4-OH-MiPT & 20.09 & $\mathrm{C}_{14} \mathrm{H}_{20} \mathrm{~N}_{2} \mathrm{O}$ & 232.32 & 86 \\
\hline
\end{tabular}

Conditions: Capillary column: $30 \mathrm{~m}$ x $250 \mu \mathrm{m}$ x $0.25 \mu \mathrm{m}$ nominal, HP-5MS 5\% phenyl methyl siloxane; mobile phase: helium; temperature profile: $1 \mathrm{~min}$ $50^{\circ} \mathrm{C}, 10^{\circ} \mathrm{C} / \mathrm{min}$ to $310^{\circ} \mathrm{C}, 3 \mathrm{~min}$ postrun; flow: $0.8 \mathrm{ml} / \mathrm{min}$; injection: $1 \mu \mathrm{l}$.

\section{Analysis of tryptamines by high-performance liquid chromatography}

Based on previous research, different mobile phases consisting of phosphate-buffers (e.g. $13 \mathrm{mM}, 26 \mathrm{mM}, 39 \mathrm{mM}$ ) or TEAA-buffers with organic solvents such as methanol or acetonitrile in various ratios were used. We started with a mobile phase consisting of phosphate buffer (13 mM, pH 2.5) and acetonitrile (80:20). However, this composition led to a marked peak tailing. To improve peak shape, $10 \%$ methanol were added. Retention times increased and tailing got worse. After optimization experiments of the mobile phase still no optimal results were obtained. In a next step, in order to check the influence of different buffers, the phosphate buffer was replaced by a $0.1 \%$ TEAA buffer. With the final composition of $0.1 \%$ TEAA buffer ( $\mathrm{pH}$ 2.5): MeOH: ACN (70:10:20), suitable retention times as well as good peak shapes were obtained. $10 \%$ Methanol were added to the mobile phase to increase selectivity. Retention times ranged between 2 and 19 minutes. In Table 3 optimized results of the analysed tryptamines are shown. Besides single determination, simultaneous separation up to 8 tryptamines was feasible (Fig. 2).

Table 3: Retention time of 17 tryptamines analysed by HPLC.

\begin{tabular}{cc} 
Analytes & $\mathbf{t}_{\text {Ret }}(\mathbf{m i n})$ \\
4-AcO-DET & 4.39 \\
4-AcO-DiPT & 6.33 \\
4-AcO-DPT & 8.69 \\
AMT & 3.53 \\
DALT & 7.32 \\
DiBT & 18.73 \\
DPT & 9.61 \\
5-API & 2.98 \\
5-MeO-DALT & 6.36 \\
5-MeO-DiPT & 6.05 \\
5-MeO-DMT & 3.24 \\
4-MeO-MiPT & 6.54 \\
5-MeO-MiPT & 4.26 \\
MiPT & 4.56 \\
$N$-OH-AMT & 4.26 \\
4-OH-MET & 2.76 \\
4-OH-MiPT & 3.03 \\
\hline
\end{tabular}

Conditions: Column: LiChrospher ${ }^{\circledR} 100 \mathrm{RP}-18 \mathrm{e}, 250 \mathrm{~mm}$ x $4 \mathrm{~mm}$; mobile phase: $0.1 \%$ TEAA ( $\mathrm{pH} 2.5)$ : methanol : acetonitrile (70:10:20); flow: 1 $\mathrm{ml} / \mathrm{min}$; temperature: $35^{\circ} \mathrm{C}$; UV: $280 \mathrm{~nm}$; injection: $5 \mu \mathrm{l}$.

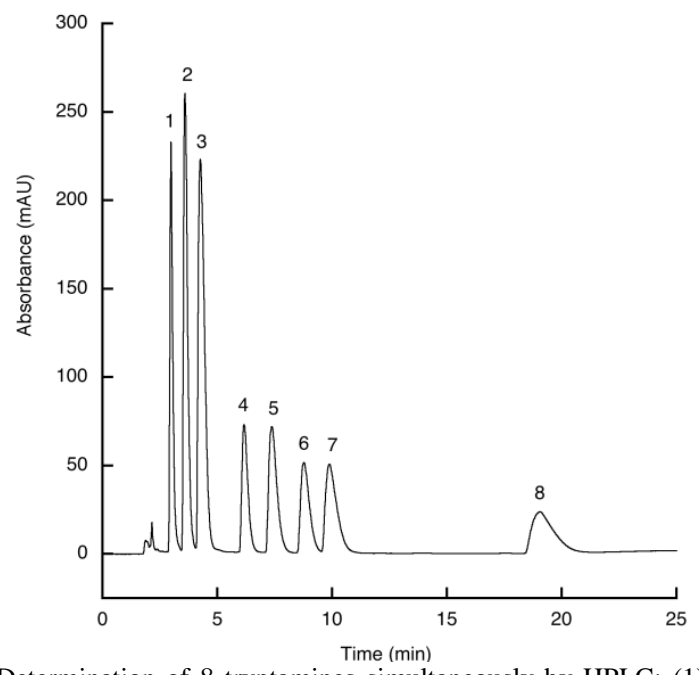

Fig. 2: Determination of 8 tryptamines simultaneously by HPLC: (1) 5-API, (2) AMT, (3) N-OH-AMT, (4) 5-MeO-DiPT, (5) DALT, (6) 4-AcO-DPT, (7) DPT, (8) DiBT. Conditions: Column: LiChrospher ${ }^{\circledR} 100 \mathrm{RP}-18 \mathrm{e}, 250 \mathrm{~mm}$ x 4 $\mathrm{mm}$; mobile phase: $0.1 \%$ TEAA ( $\mathrm{pH} 2.5)$ : methanol : acetonitrile (70:10:20); flow: $1 \mathrm{ml} / \mathrm{min}$; temperature: $35^{\circ} \mathrm{C}$; UV: $280 \mathrm{~nm}$; injection: $5 \mu \mathrm{l}$.

Additionally, a validation of the method by means of 4AcO-DiPT was performed (Table 4). The relative standard deviation (RSD) of the intra- and interday retention time was between $0.13 \%$ and $0.70 \%$. To check reproducibility, the analyte was injected 20 times a day, where $0.27 \%$ RSD of the retention time was obtained. 
The proposed HPLC method is advantageous, since due to the isocratic conditions it is very economical compared to other approaches described in literature. There are articles dealing with similar separation techniques of tryptamine derivatives but they report on gradient elution which is more complex (Hsiao et al., 2009; Wang et al., 2008). A further benefit of the present method is the opportunity to distinguish between the two isomeric compounds AMT and 5-API. Also, Elliott et al. (2013) described the analytical challenge for forensic analysis to differentiate these two analytes.

Comparing HPLC and GC separation results, retention times of both methods are quite short and provide clear information about identity. Simultaneous separation up to a maximum of 8 tryptamines was achieved.

Table 4: Repeatability and reproducibility data including the retention time by means of 4-AcO-DiPT.

\begin{tabular}{cc}
\hline Repeatability & $\mathbf{t}_{\text {Ret }}(\mathbf{m i n})$ \\
\hline Intraday $\mathrm{n}=5$ & $6.37 \pm 0.01, \mathrm{RSD}=0.13 \%$ \\
Interday $\mathrm{n}=10$ & $6.42 \pm 0.05, \mathrm{RSD}=0.70 \%$ \\
\hline Reproducibility & $\mathbf{t}_{\text {Ret }}(\mathbf{m i n})$ \\
\hline Intraday $\mathrm{n}=20$ & $6.40 \pm 0.02, \mathrm{RSD}=0.27$ \\
\hline
\end{tabular}

Conditions: Column: LiChrospher ${ }^{\circledR} 100 \mathrm{RP}-18 \mathrm{e}, 250 \mathrm{~mm}$ x $4 \mathrm{~mm}$; mobile phase: $0.1 \%$ TEAA (pH 2.5) : methanol : acetonitrile (70:10:20); flow: 1 $\mathrm{ml} / \mathrm{min}$; temperature: $35^{\circ} \mathrm{C}$; UV: $280 \mathrm{~nm}$; injection: $5 \mu \mathrm{l}$.

\section{Enantioseparation of 5-API, AMT and N-OH-AMT by HPLC- UV}

Enantioseparation of 5-API, AMT and $\mathrm{N}$-OH-AMT was performend using two different direct chiral separation methods. As first approach a chiral Astec ${ }^{\circledR}$ Cyclobond ITM 2000, modified with native $\beta$-cyclodextrin was applied for enantioseparation experiments. As second approach, based on previous chiral separation studies, sulfated $\beta$-cyclodextrin was used as chiral mobile phase additive using a common RP-18e, 250 x $4 \mathrm{~mm}$ column as stationary phase (Taschwer et al., 2014).

A mobile phase consisting of $1 \%$ TEAA buffer ( $\mathrm{pH} 4.1$ ) and methanol was used for optimization process of the Astec ${ }^{\circledR}$ Cyclobond ITM 2000 column. Therefore the mobile phase ratio was adjusted as well as the flow and the injection volume were optimized. With the final composition of the mobile phase $1 \%$ TEAA buffer (pH 4.1) and methanol (99:1) baseline separation of 5-API was achieved. The retention times of the two peaks were $9.77 \mathrm{~min}$ and $10.53 \mathrm{~min}\left(\mathrm{R}_{\mathrm{s}}=1.72\right) . \mathrm{N}-\mathrm{OH}-\mathrm{AMT}$ was partially separated within 9 minutes $\left(8.00 \mathrm{~min}\right.$ and $\left.8.32 \mathrm{~min} ; \mathrm{R}_{\mathrm{s}}=1.10\right)$. In Fig. 3, a chromatogram of the enantioseparation of 5-API is presented. Obviously AMT showed too little interaction with the stationary phase. Hence no chiral separation was obtained (6.66 min). Finally, the method was validated by means of 5-API. In Table 5 repeatability as well as reproducibility data of the retention times and the resolution factor are shown.

With the second approach using sulfated $\beta$-cyclodextrin as mobile phase additive 5-API was only partially separated, AMT and $\mathrm{N}-\mathrm{OH}-\mathrm{AMT}$ showed no chiral separation.

Chiral separation results obtained with the Astec ${ }^{\circledR}$ Cyclobond ITM 2000 column might be a possible evidence that the psychoactive compounds had their origin in a clandestine laboratory as non-enantioselective synthesis is easier and cheaper. Although AMT was not chirally separated by the presented methods, there is evidence for a racemic mixture as it was already baseline separated into its enantiomers by former CE experiments in our group using sulfated $\beta$-cyclodextrin as chiral additive in the background electrolyte (unpublished results).

With the introduced methods it was feasible to elucidate real life samples (AMT, 5-MeO-MiPT, DMT) seized by Austrian police and to give further background concerning the syntheses and the origin of the psychoactive compounds.

Table 5: Repeatability and reproducibility data including the retention time and resolution by means of 5-API using the Astec ${ }^{\circledR}$ Cyclobond ITM 2000 column.

\begin{tabular}{lccc}
\hline Repeatability & $\mathbf{t}_{\mathbf{1}}$ (min) & $\mathbf{t}_{\mathbf{2}}(\mathbf{m i n})$ & $\mathbf{R}_{\mathbf{s}}$ \\
\hline \multirow{2}{*}{ Intraday $\mathrm{n}=5$} & $9.77 \pm 0.01$, & $10.53 \pm 0.01$, & $1.72 \pm 0.02$, \\
& $\mathrm{RSD}=0.07 \%$ & $\mathrm{RSD}=0.08 \%$ & $\mathrm{RSD}=1.08 \%$ \\
\multirow{2}{*}{ Interday $\mathrm{n}=10$} & $9.66 \pm 0.13$, & $10.39 \pm 0.15$, & $1.72 \pm 0,02$, \\
& $\mathrm{RSD}=1.30 \%$ & $\mathrm{RSD}=1.40 \%$ & $\mathrm{RSD}=1.00 \%$ \\
\hline Reproducibility & $\mathbf{t}_{\mathbf{1}}(\mathbf{m i n})$ & $\mathbf{t}_{\mathbf{2}}(\mathbf{m i n})$ & $\mathbf{R}_{\mathbf{s}}$ \\
\hline \multirow{2}{*}{ Intraday $\mathrm{n}=20$} & $9.49 \pm 0.03$, & $10.21 \pm 0.03$, & $1.71 \pm 0,02$, \\
& $\mathrm{RSD}=0.32 \%$ & $\mathrm{RSD}=0.34 \%$ & $\mathrm{RSD}=1.43 \%$ \\
\hline
\end{tabular}

Conditions: Column: Astec ${ }^{\circledR}$ Cyclobond I ${ }^{\mathrm{TM}} 2000,250 \mathrm{~mm}$ x $4.6 \mathrm{~mm}$; mobile phase: $1 \%$ TEAA (pH 4.1): methanol (99:1); flow: $0.6 \mathrm{ml} / \mathrm{min}$; temperature: $25^{\circ} \mathrm{C}$; UV: $240 \mathrm{~nm}$; injection: $1 \mu \mathrm{l}$.

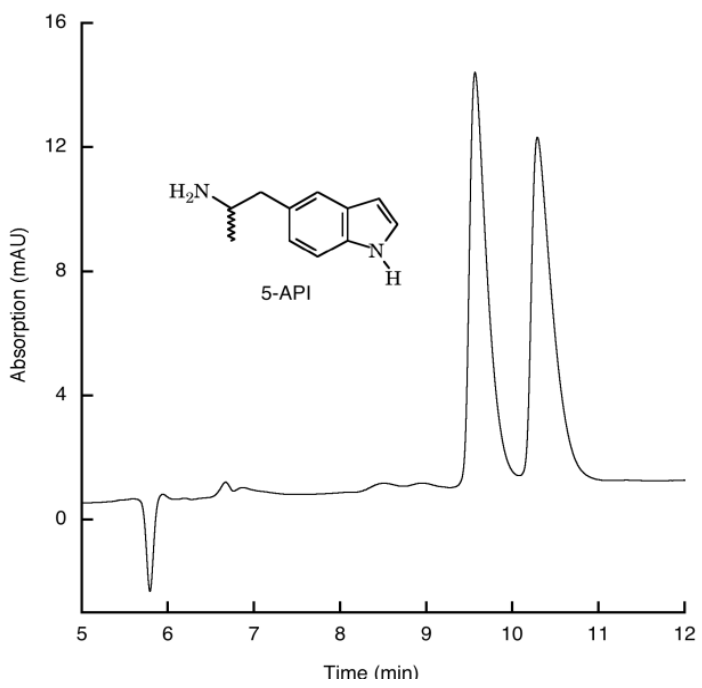

Fig. 3: Chiral separation of 5-API by HPLC-UV. Conditions: Column: Astec ${ }^{\circledR}$ Cyclobond I ${ }^{\mathrm{TM}} 2000,250 \mathrm{~mm} \times 4.6 \mathrm{~mm}$; mobile phase: $1 \%$ TEAA $(\mathrm{pH}$ 4.1): methanol (99:1); flow: $0.6 \mathrm{ml} / \mathrm{min}$; temperature: $25^{\circ} \mathrm{C}$; UV: $240 \mathrm{~nm}$; injection: $1 \mu$ l.

\section{CONCLUSION}

Based on natural occurring tryptamines e.g. in toads, fungi and cacti, new chemically designed synthetic tryptamine derivatives have become a competitive compound class of abused drugs in recent years. Many of these substances are legal and as they induce similar psychotropic effects like illegal recreational drugs, they have become very popular in the scene. For many of the NPDs only few analytical methods for identification are available. Consequently, there is a demand to develop new chromatographic separation methods. In the course of this research 
tryptamine derivatives, obtained by mystery shopping, were analysed by GC-MS. It was verified that all 13 compounds were in accordance with the specified identity given by the online vendors. Separation was carried out with HPLC by developing quite an inexpensive and simple method. The introduced approaches provide a good opportunity for identification and separation of new tryptamines. Run times are rather short and the tryptamines are clearly distinguishable.

Additionally, a chiral separation method was developed to provide further information concerning the quality and origin of 5-API, AMT and $\mathrm{N}$-OH-AMT. The presented enantioseparation results verify the fact that recreational drugs are sold as racemic mixtures which is in conformity with results of NPDs reported in other publications (Taschwer et al., 2014; Weiss et al., 2015; Taschwer et al., 2014; Aturki et al., 2014).

\section{ACKNOWLEDGEMENT}

This work is dedicated to Austrian public prosecution.

\section{Declaration/Conflict of Interest}

The authors have declared no conflict of interest.

\section{REFERENCES}

Adamovicz P, Tokarczyk B. Simple and rapid screening procedure for 143 new psychoactive substances by liquid chromatographytandem mass spectrometry. Drug Test Anal, 2015; Doi: 10.1002/dta.1815.

Ambach L, Redondo AH, König S, Angerer V, Schürch S, Weinmann W. Detection and quantification of 56 new psychoactive substances in whole blood and urine by LC-MS/MS. Bioanalysis, 2015; 7: 1119-1136.

Araujo AM, Carvalho F, De Bastos LM, De Pinho PG, Carvalho M. The hallucinogenic world of tryptamines: an updated review. Arch Toxicol, 2015; 89: 1151-1173.

Armenta S, Garrigues S, De la Guardia M, Brassier J, Alcala M, Blanco M, Perez-Alfonso C, Galipienso N. Detection and characterization of emerging psychoactive substances by ion mobility spectrometry. Drug Test Anal, 2015; 7: 280-289.

Arunotayanun W, Dalley JW, Huang XP, Setola V, Treble R, Iversen L, Roth BL, Gibbons S. An analysis of the synthetic tryptamines AMT and 5-MeO-DALT: emerging 'Novel Psychoactive Drugs'. Bioorg Med Chem Lett, 2013; 23: 3411-3415.

Arunotayanun W, Gibbons S. Natural product 'legal highs'. Nat Prod Rep, 2012; 29: 1304-1316.

Aturki Z, Schmid MG, Chankvetadze B, Fanali S. Enantiomeric separation of new cathinone derivatives designer drugs by capillary electrochromatography using a chiral stationary phase, based on amylose tris (5-chloro-2-methylphenylcarbamate). Electrophoresis, 2014; 35: 3242 3249 .

Brandt SD, Martins CPB. Analytical methods for psychoactive N,N-dialkylated tryptamines.Trends in Anal Chem, 2010; 29: 858-869.

Brandt SD, Moore SA, Freeman S, Kanu AB. Characterization of the synthesis of N,N-dimethyltryptamine by reductive amination using gas chromatography ion trap mass spectrometry. Drug Test Anal, 2010; 2: 330-338.

Brandt SD, Tearavarich R, Dempster N, Cozzi NV, Daley PF. Synthesis and characterization of 5-methoxy-2-methyl-N,N-dialkylated tryptamines. Drug Test Anal, 2012; 4: 24-32.

Elliott SP, Brandt SD, Freeman S, Archer RP. AMT (3- (2aminopropyl)indole) and 5-IT (5- (2-aminopropyl)indole): an analytical challenge and implications for forensic analysis. Drug Test Anal, 2013; 5: 196-202.
EMCDDA. European Drug Report - Trends and Developments.

2015.

Gambelunghe C, Aroni K, Rossi R, Moretti L, Bacci M. Identification of $\mathrm{N}, \mathrm{N}$-dimethyltryptamine and beta-carbolines in psychotropic ayahuasca beverage. Biomed Chromatogr, 2008; 22:1056-59.

Gaujac A, Dempster N, Navickiene S, Brandt SD, De Andrade JB. Determination of N,N-dimethyltryptamine in beverages consumed in religious practices by headspace solid-phase microextraction followed by gas chromatography ion trap mass spectrometry. Talanta, 2013;106:394-98.

Gibbons S. 'Legal highs'-novel and emerging psychoactive drugs: a chemical overview for the toxicologist. Clin Toxicol (Phila), 2012; 50: 15-24.

Hsiao Y, Liu JT, Lin CH. Simultaneous separation and detection of 18 phenethylamine/tryptamine derivatives by liquid chromatography-UV absorption and -electrospray ionization mass spectrometry. Anal Sci, 2009; 25: 759-763.

Kanu AB, Brandt SD, Williams MD, Zhang N, Hill HH. Analysis of psychoactive cathinones and tryptamines by electrospray ionization atmospheric pressure ion mobility time-of-flight mass spectrometry. Anal Chem, 2013; 85: 8535-8542.

Manske RHF. A synthesis of the methyltryptamines and some derivatives. Can J of Res, 1931; 5: 592-600.

McIlhenny EH, Pipkin KE, Standish LJ, Wechkin HA, Strassman R, Barker SA. Direct analysis of psychoactive tryptamine and harmala alkaloids in the Amazonian botanical medicine ayahuasca by liquid chromatography-electrospray ionization-tandem mass spectrometry. J Chromatogr A, 2009; 1216: 8960-8968.

Pires AP, De Oliveira CD, Moura S, Dorr FA, Silva WA, Yonamine M. Gas chromatographic analysis of dimethyltryptamine and beta-carboline alkaloids in ayahuasca, an Amazonian psychoactive plant beverage. Phytochem Anal, 2009; 20: 149-153.

Salikov RF, Belyy AY, Khusnutdinova NS, Vakhitova YV, Tomilov YV. Synthesis and cytotoxic properties of tryptamine derivatives. Bioorg Med Chem Lett, 2015; 25: 3597-3600.

Shulgin A, Shulgin A. 1991. PiHKAL - A chemical love story. California, United States: Transform Press, Berkeley.

Shulgin A, Shulgin A. 1997. TiHKAL-The continuation. California, United States: Transform Press, Berkeley.

Taschwer M, Hofer MG, Schmid MG. Enantioseparation of benzofurys and other novel psychoactive compounds by $\mathrm{CE}$ and sulfobutylether beta-cyclodextrin as chiral selector added to the BGE. Electrophoresis, 2014; 35: 2793-2799.

Taschwer M, Seidl Y, Mohr S, Schmid MG. Chiral separation of cathinone and amphetamine derivatives by HPLC/UV using sulfated $\beta$ cyclodextrin as chiral mobile phase additive. Chirality, 2014; 26: 411-418.

Tearavarich R, Hahnvajanawong V, Dempster N, Daley PF, Cozzi NV, Brandt SD. Microwave-accelerated preparation and analytical characterization of 5-ethoxy-N,N-dialkyl-[alpha,alpha,beta,beta-H (4) ]and [alpha,alpha,beta,beta-D (4) ]-tryptamines. Drug Test Anal, 2011; 3: 597-608.

UNODC. The challenge of new psychoactive substances. 2013.

Wang MJ, Liu JT, Chen HM, Lin JJ, Lin CH. Comparison of the separation of nine tryptamine standards based on gas chromatography, high performance liquid chromatography and capillary electrophoresis methods. J Chromatogr A, 2008; 1181: 131-136.

Weiss JA, Mohr S, Schmid MG. Indirect chiral separation of new recreational drugs by gas chromatography-mass spectrometry using trifluoroacetyl-L-prolyl chloride as chiral derivatization reagent. Chirality, 2015; 27: 211-215.

\section{How to cite this article:}

Taschwer M, Ebner E, Schmid MG. Test purchase of new synthetic tryptamines via the Internet: Identity check by GC-MS and separation by HPLC. J App Pharm Sci, 2016; 6 (01): 028-034. 